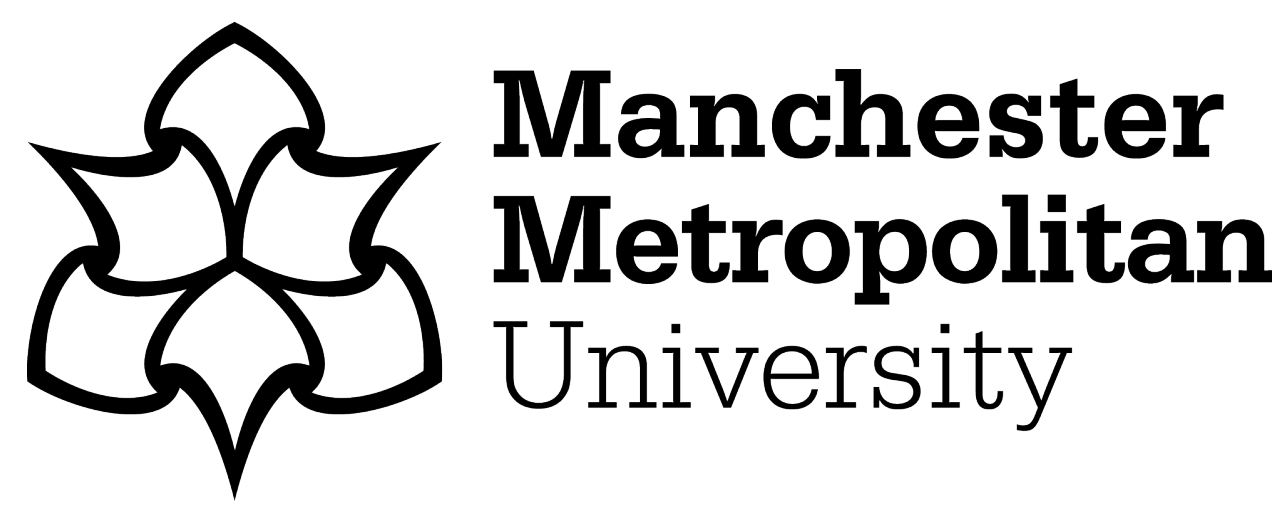

Saubade, F, Humblot, C, Hemery, YM and Guyot, JP (2017) PCR screening of an African fermented pearl-millet porridge metagenome to investigate the nutritional potential of its microbiota. International Journal of Food Microbiology, 244. pp. 103-110. ISSN 0168-1605

Downloaded from: https://e-space.mmu.ac.uk/621882/

Version: Accepted Version

Publisher: Elsevier

DOI: https://doi.org/10.1016/j.ijfoodmicro.2016.12.020

Usage rights: Creative Commons: Attribution-Noncommercial-No Derivative Works 4.0

Please cite the published version 


\section{PCR screening of an African fermented pearl-millet porridge metagenome to investigate the nutritional potential of its microbiota}

Fabien Saubade ${ }^{1}$, Christèle Humblot ${ }^{1}$, Youna M. Hemery ${ }^{1}$, Jean-Pierre Guyot ${ }^{1 *}$

${ }^{1}$ Institute of Research for Development (IRD); UMR 204 Food and nutrition research in the global South (NUTRIPASS), IRD / University of Montpellier / SupAgro, BP 64501, 911 avenue Agropolis, 34394 Montpellier Cedex 5, France

* Corresponding author.

Phone: +33 467416285, Fax: +33 467416157, Email: jean-pierre.guyot@ird.fr 


\begin{abstract}
Cereals are staple foods in most African countries, and many African cereal-based foods are spontaneously fermented. The nutritional quality of cereal products can be enhanced through fermentation, and traditional cereal-based fermented foods (CBFFs) are possible sources of lactic acid bacteria (LAB) with useful nutritional properties. The nutritional properties of $\mathrm{LAB}$ vary depending on the species and even on the strain, and the microbial composition of traditional CBFFs varies from one traditional production unit (TPU) to another. The nutritional quality of traditional CBFFs may thus vary depending on their microbial composition.
\end{abstract}

As the isolation of potentially useful LAB from traditional CBFFs can be very time consuming, the aim of this study was to use PCR to assess the nutritional potential of LAB directly on the metagenomes of pearl-millet based fermented porridges (ben-saalga) from Burkina Faso. Genes encoding enzymes involved in different nutritional activities were screened in 50 metagenomes extracted from samples collected in 10 TPUs in Ouagadougou. The variability of the genetic potential was recorded. Certain genes were never detected in the metagenomes (genes involved in carotenoid synthesis) while others were frequently detected (genes involved in folate and riboflavin production, starch hydrolysis, polyphenol degradation). Highly variable microbial composition - assessed by real-time PCR - was observed among samples collected in different TPUs, but also among samples from the same TPU. The high frequency of the presence of genes did not necessarily correlate with in situ measurements of the expected products. Indeed, no significant correlation was found between the microbial variability and the variability of the genetic potential. In spite of the high rate of detection (80\%) of both genes folP and folK, encoding enzymes involved in folate synthesis, the folate content in ben-saalga was rather low (median: $0.5 \mu \mathrm{g} / 100 \mathrm{~g}$ fresh weigh $\mathrm{t}$ basis). This work highlighted the limit of evaluating the nutritional potential of the microbiota of traditional fermented foods by the only screening of genes in metagenomes, and suggests that such a screening should be completed by a functional analysis.

Key-words: vitamin B9; real-time PCR; Lactobacillus fermentum; yeasts, Pennisetum glaucum; starch metabolism 


\section{Introduction}

Cereal based fermented foods (CBFFs) are staple food products in many African countries (Guyot, 2012). Some are used as complementary foods for children under five during the period of breast feeding (Mouquet-Rivier et al., 2008; Svanberg, 1995). These foods are mainly fermented by naturally occurring lactic acid bacteria (LAB) (Guyot, 2012; Minervini et al., 2015). For example, the bacteria responsible for spontaneous fermentation in different foods (ben-saalga, koko, fura) made from pearl-millet (Pennisetum glaucum) belong to genus Lactobacillus, Weissella, Leuconostoc, Lactococcus and Pediococcus, with Lactobacillus fermentum frequently found to be the dominant species (Humblot and Guyot, 2009; Lei and Jakobsen, 2004; Owusu-Kwarteng et al., 2012). It has been shown that the composition of the microbiota of pearl-millet based fermented foods can vary from one traditional production unit (TPU) to another (Humblot and Guyot, 2009; Owusu-Kwarteng et al., 2012). These differences could be due to different factors, including the raw materials used for the preparation of the CBFF (Owusu-Kwarteng et al., 2012).

As reported in a review by Singh et al. (2015), the nutritional quality of cereals can be enhanced through fermentation by LAB. A set of genes coding for enzymes involved in nutritional functions was screened in 152 LAB strains isolated from ben-saalga and showed that the presence or absence of certain genes depended on the species (Turpin et al., 2011). For example, the genes folP and folK encoding enzymes involved in the synthesis of folate were detected in $100 \%$ of the L. fermentum strains $(\mathrm{n}=70)$ isolated from ben-saalga. On the contrary, the gene mall encoding an enzyme involved in the hydrolysis of dextrins and isomaltose was detected only in $7 \%$ of the same strains. Therefore, if the genetic potential of these strains is confirmed by phenotypical analysis, the nutritional quality of this CBFF could vary depending on the LAB species responsible for the fermentation. Considering the variations in the composition of the microbiota, the nutritional quality may also vary from one TPU to another.

The genetic potential of the bacteria responsible for fermentation may be estimated by PCR screening of genes in metagenomes extracted directly from fermented foods (Turpin et al., 2011). However, in the preliminary work of Turpin et al. (2011) this method was only tested on five samples of pearl-millet based fermented porridges. The objective of the present work was to evaluate the nutritional potential of bacteria directly on the metagenomes of 50 
samples collected in 10 TPUs in Burkina Faso using PCR screening. The main bacteria involved in the fermentation of the CBFF products were quantified using real-time PCR. Finally, to validate genetic screening using one simple function, we measured the folate (vitamin B9) content of the samples to check for a relationship between an identified genetic potential and the nutritional reality. Folate is of particular importance since folate deficiency leads to neural tube defects, congenital malformations and megaloblastic anemia, and is still prevalent in many countries (Arsenault et al., 2014; Becquey and Martin-Prevel, 2010; Blount et al., 1997; Rouget et al., 2005; Viñas et al., 2011; Wickramasinghe, 2006).

\section{Material and methods}

\subsection{Samples of fermented porridges}

The traditional processing of pearl-millet into ben-saalga is well known (Tou et al., 2006). The final steps are spontaneous fermentation, mainly due to LAB (Lactobacillus, Weissella, Leuconostoc, Lactococcus and Pediococcus) and to a lesser extent yeasts, and a cooking step before consumption (Humblot and Guyot, 2009; Tou et al., 2006). Ten traditional production units (TPUs) were randomly selected in different parts of Ouagadougou (Burkina Faso) based on a previous survey (Tou et al., 2006). For each TPU, five samples of porridges were collected after the cooking step (i.e. food as sold and consumed), on different days. Therefore, the 5 samples collected in a same TPU corresponded to fermentations that occurred on five different days. They were conserved at $-20{ }^{\circ} \mathrm{C}$ until DNA and folate extraction. The 50 pearlmillet porridge samples were coded with a letter from A to $\mathbf{J}$ (corresponding to the TPU) followed by a number from 1 to 5 (corresponding to the day of sampling). Although for example, samples A1 and B1, are both numbered 1, this does not necessarily mean they were collected on the same day.

\subsection{Nucleic acid extraction}

Total DNA was extracted from $20 \mathrm{~g}$ of porridge in two steps after serial centrifugation to eliminate starch and using the Wizard genomic DNA purification kit (Promega, Charbonnières, France) with an additional lysis step using an amalgamator with zirconium beads (VWR, Fontenay-sous-Bois, France), as previously described (Turpin et al., 2011). DNA concentrations and purity were estimated by measuring absorbance at 260 and $280 \mathrm{~nm}$ 
(NanoVue ${ }^{\mathrm{TM}}$, GE Healthcare, Uppsala Sweden). The DNA samples were then stored at $-20{ }^{\circ} \mathrm{C}$ until PCR and real-time PCR analysis.

\subsection{PCR amplification for the detection of genes of interest}

A set of genes of nutritional interest was selected. These genes are involved in the synthesis of carotenoids, folate and riboflavin (vitamin B2), in starch metabolism, and tannase synthesis. The genes were detected by PCR using primers selected from a previous work (Turpin et al., 2011) and are listed in Table 1. PCR conditions were the same as those described in Turpin et al. (2011).

\subsection{Real-time PCR for the quantification of $L A B$}

Different Bacteria, and especially LAB, are involved in the fermentation of ben-saalga, including Lactobacillus (especially L. plantarum and L. fermentum), Weissella, Leuconostoc, Lactococcus and Pediococcus (Humblot and Guyot, 2009; Turpin et al., 2011). We selected primers corresponding to these groups, genera and species in the literature, and checked them in silico. We were unable to find any primers sufficiently specific for Lactococcus and Pediococcus since in silico, their sequences matched other genera or species present in our ecosystem. The primers validated in silico are listed in the Table 2.

The strains L. plantarum ATCC14917T, L. fermentum ATCC14931, Leuconostoc mesenteroides ATCC10880, Pediococcus pentosaceus ATCC43200 and Weissella confusa ATCC10881T were used to generate quantification matrixes, by extracting DNA from samples of pearl-millet flour suspensions in water mixed with each bacterium at different concentrations. The specificity of each previously selected primer (Table 2) was checked by real-time PCR using the DNA extracted from the reference strains and a negative control (sterile water). When necessary, the primers were converted into their reverse complement to perform real-time PCR. For each reaction, $5 \mu \mathrm{L}$ of the extracted template-DNA was added to $20 \mu \mathrm{L}$ of PCR mix containing 1X Mesa green q-PCR Master Mix Plus and $0.3 \mu \mathrm{M}$ of each primer (Eurogentec, Angers, France). The PCR conditions used were $10 \mathrm{~min}$ at $95{ }^{\circ} \mathrm{C}$ and 40 cycles of $15 \mathrm{~s}$ at $95{ }^{\circ} \mathrm{C}$, then $1 \mathrm{~min}$ at $55^{\circ} \mathrm{C}$, followed by a dissociation curve from $55{ }^{\circ} \mathrm{C}$ to $95{ }^{\circ} \mathrm{C}$. No template controls (NTC), using water instead of DNA, were included in each plate. 
The efficiency of the real-time PCR ranged from $79 \%$ to $102 \%$ and the correlation coefficients were higher than 0.990 . The detection limit was between $10^{2}$ and $10^{3}$ bacteria equivalent (Colony forming unit, CFU) per $g$ of porridge depending on the primer.

The primers validated on DNA extracted from reference strains were used for DNA extracted from the 50 samples to estimate bacterial concentrations.

\subsection{Total folate assay}

The total folate content of the 50 samples was determined in triplicate using the microbiological assay described by Kariluoto and Piironen (2009), modified as follows. Frozen samples were thawed, $1 \mathrm{~g}$ was weighed in a 50-ml centrifuge tube, $15 \mathrm{ml}$ of extraction buffer were added (50 mM Ches/50mM Hepes buffer, $10 \mathrm{mM}$ 2-mercaptoethanol, $2 \%$ (w/v) sodium ascorbate, $\mathrm{pH}$ 7.85), the tubes were flushed with nitrogen and thoroughly vortexed. The tubes were heated at $100{ }^{\circ} \mathrm{C}$ for $10 \mathrm{~min}$, then cooled on ice. The $\mathrm{pH}$ was adjusted to 4.7 with acetic acid and $1 \mathrm{ml}$ of $\alpha$-amylase (Sigma-Aldrich A9857, $20 \mathrm{mg} / \mathrm{ml}$ in 1\% sodium ascorbate) and $2 \mathrm{ml}$ of conjugase (prepared from desiccated hog kidney, $5 \mathrm{mg} / \mathrm{ml}$ in water) were added. The tubes were flushed with nitrogen and incubated for $3 \mathrm{~h}$ at $37{ }^{\circ} \mathrm{C}$ in a shaking water bath in the dark. Then $2 \mathrm{ml}$ of protease (Sigma-Aldrich P5147, $3 \mathrm{mg} / \mathrm{ml}$ in 1\% sodium ascorbate) were added. The tubes were flushed with nitrogen and incubated at $37{ }^{\circ} \mathrm{C}$ in a shaking water bath in the dark for $1 \mathrm{~h}$. At the end of the incubation, the tubes were heated at $100{ }^{\circ} \mathrm{C}$ for $5 \mathrm{~min}$ to inactivate the enzymes, then cooled on ice. The $\mathrm{pH}$ was adjusted to 6.1 with $\mathrm{KOH}$, the volume was brought to exactly $50 \mathrm{ml}$ with $0.5 \%$ sodium ascorbate (pH 6.1), and the tubes were centrifuged at $20,000 \mathrm{~g}$ at $4{ }^{\circ} \mathrm{C}$ for $30 \mathrm{~min}$. The supernatants were then diluted with $0.5 \%$ sodium ascorbate $(\mathrm{pH} 6.1)$, and the method described by Kariluoto and Piironen (2009) was used to determine the total concentration of folate using 96-well microtiter plates, with Lactobacillus rhamnosus ATCC 7469 as the growth indicator organism, folic acid (Sigma-Aldrich, St Louis, MI, USA) as the calibrant, and Folic Acid Casei Medium (Difco, Sparks, MD, USA) as the assay medium. After $18 \mathrm{~h}$ of incubation at 37 ${ }^{\circ} \mathrm{C}$, turbidity was measured with a microplate reader at $590 \mathrm{~nm}$ and the values were compared to a standard curve to calculate the concentration of folate. The reliability of the method was confirmed by analyzing a certified reference material (BCR 121 Wholemeal flour, IRMM, Geel, Belgium). A blank sample and the reference sample were analyzed in each set of samples. 
The dry matter content of each sample was determined in triplicate by drying the samples in an oven at $105^{\circ} \mathrm{C}$ until constant weight.

\subsection{Statistical analysis}

Statistical analyses were performed using Statgraphics Plus 5.1 software (Rockville, MD, USA). One-way analyses of variance (ANOVA), followed by least significant difference tests (LSD), were carried out to identify the differences between samples. Differences were considered statistically significant for $\mathrm{p}$-values $<0.05$. Linear correlation tests were also carried out using Pearson's correlation method with a 95\% confidence interval. Correlation coefficients (r) were considered significant at $\mathrm{p}$-values $<0.05$. A principal component analysis (PCA) was performed with R 3.2.2 on the real-time PCR data and a Hierarchical Clustering on Principle Components (HCPC) was also carried out, to separate the samples into statistically different groups, depending on the composition of their microbiota.

\section{Results}

\subsection{Detection of genes coding for enzymes involved in nutritional functions}

The nutritional potential of the microbiota of the 50 samples was assessed by screening for the presence or absence of 15 genes. The results of gene detection are presented in Table 3 . Even if the primers used were designed to be species specific, there were a few nonspecific detections among the 50 metagenomes. In this study, we considered that a gene was detected even if the detection was nonspecific.

The frequency of detection of the different genes in the metagenomes varied depending on the function. Indeed, the operon crtNM, encoding dehydrosqualene desaturase and dehydrosqualene synthase, was never detected, suggesting that the LAB present in the bensaalga samples were not able to synthesize carotenoids. The genetic potential of these LAB to synthesize tannases was higher since the gene tanlpl, encoding a tannin acyl hydrolase, was detected in $56 \%$ of the metagenomes. The LAB displayed a good genetic potential to hydrolyze starch, since the genes $a g l, g l g P$ and $\operatorname{dexC}$ (encoding alpha-glucosidase, glycogen phosphorylase and neopullulanase, respectively) were detected in $74 \%, 94 \%$ and $86 \%$ of the metagenomes, respectively. However, the genes $\alpha$-amy and $a m y E$ (encoding intra and 
extracellular alpha-amylases, respectively) were detected in only $24 \%$ and $0 \%$ of the metagenomes, respectively. The genetic potential to hydrolyze maltose and dextrin was lower, since the genes malP and malL (encoding maltose phosphorylase and oligo-1,6-glucosidase, respectively) were detected in $26 \%$ and $54 \%$ of the metagenomes respectively. Four genes are required for the biosynthesis of riboflavin (Burgess et al., 2009; Capozzi et al., 2012), and some, such as ribH (encoding 6.7-dimethyl-8-ribityllumazine synthase), were very frequently detected (92\%) in the metagenomes. However, the low frequency of detection of the gene ribG (encoding diaminohydroxyphosphoribosylaminopyrimidine deiminase; 38\%), indicates that the LAB in these samples of ben-saalga have a low genetic potential to synthesize riboflavin. Conversely, since the two genes folP and folK (encoding dihydropteroate synthase/ dihydropteroate pyrophosphorylase and 2-amino-4-hydroxy-6hydroxymethyldihydropteridine diphosphokinase, respectively) were detected in $80 \%$ of the samples, the LAB responsible for the ben-saalga fermentation have a high genetic potential to synthesize folate.

\subsection{Quantification of targeted LAB populations by real-time PCR}

Primers available in the literature and checked in silico were tested to quantify Bacteria, the LAB group and the LAB genus and species commonly associated with pearl-millet based fermented foods by real-time PCR (Table 2). Quantification of Bacteria, LAB group and the Lactobacillus genus was not possible since there was no linear relationship between the number of bacteria cells and the number of cycles needed to reach a detectable amount of PCR products $(\mathrm{Ct})$. After in silico verification, we found that primers designed for Bacteria LAB and Lactobacillus also matched chloroplasts from sorghum, which is very close to pearl millet. Thus, we decided not to use them in this study. Only the calibration curves obtained for the Leuconostoc and Weissella genus and L. plantarum and L. fermentum species enabled further analysis of the porridge samples (Table 2).

The concentration of microorganisms varied with the sample and was generally lower than $10^{5} \mathrm{CFU} / \mathrm{g}$ of porridge (Figure 1). L. fermentum was detected in $88 \%$ of the samples and was the dominant microorganism. Leuconostoc sp. was detected in $60 \%$ of the samples, but in none of the samples from TPU C. L. plantarum was detected in $32 \%$ samples, but in none of the samples from TPU C, F, G and J. Weissella sp. was detected in 30\% samples, but in none of the samples from TPU C, E, G and J. 
The microbiota differed among the samples from the different TPUs. For example, the samples produced in TPU $\mathrm{C}$ had the lowest concentrations of microorganisms. In this TPU, only L. fermentum was detected. In contrast, the highest concentrations of microorganisms were found in the samples from TPU H. In this TPU, all the genera and species screened were detected. In addition, we observed that the microbiota in the samples produced by the same TPU varied depending on the day the samples were taken. A principal component analysis, followed by a Hierarchical Clustering on Principle Components, was performed (data not shown) on the real-time PCR data, but it showed that the five samples of a same TPU were never grouped together, and thus that the TPUs could not be discriminated on the basis of the samples microbiota.

\subsection{Folate content of the pearl-millet porridges}

The dry matter content of the 50 samples ranged from $3 \%$ to $9 \%$ (median: $5.6 \%$ ). ANOVA showed that the dry matter content of samples differed significantly $(\mathrm{p}<0.05)$, depending on the TPU.

The folate content of the samples (Figure 2) varied from 0 to $3.3 \mu \mathrm{g} / 100 \mathrm{~g}$ fresh weight basis (median: $0.5 \mu \mathrm{g} / 100 \mathrm{~g} \mathrm{FW}$ ). We observed high variability among the samples produced by the same TPU. To determine if the folate content of samples produced by two different TPUs differed, we also compared the TPUs by pairs. The total folate contents of the samples differed significantly $(\mathrm{p}<0.05)$ among the different TPUs. A linear correlation test showed that there was a low $(\mathrm{r}=0.3)$ but statistically significant correlation $(\mathrm{p}<0.05)$ between the folate content and the dry matter content of the porridge samples. On the other hand, there was no significant correlation $(p>0.05)$ between the concentrations of the four main microorganisms investigated and the folate content of the samples.

\section{Discussion}

In this study, we estimated the genetic potential of the ben-saalga microbiota for different nutritional functions. We also quantified the main LAB described as being responsible for the fermentation of ben-saalga: L. fermentum, L. plantarum, Leuconostoc and Weissella (Humblot and Guyot, 2009; Turpin et al., 2011). As the genetic potential to synthesize folate was found to be high, we also quantified the folate content of the samples, to investigate if there was any relation between the composition of the main microorganisms investigated, the 
genes encoding for enzymes involved in folate synthesis and the folate content of the pearlmillet based porridges.

Rather high variability of genetic potential was observed among the samples taken from different TPUs, and also among samples taken from the same TPU. Some genes were detected frequently, such as $a g l, g l g P$ and $\operatorname{dexC}$ (coding for enzymes involved in starch metabolism), while others were not detected at all, such as $\operatorname{crtN}$ and $\operatorname{crtM}$ (coding for enzymes involved in carotenoid synthesis). Since the genes $\operatorname{agl}, g \lg P$ and $\operatorname{dex} C$ were often detected, the genetic potential of the microbiota of the porridge to metabolize starch appears to be high. However, in a previous study, the three genes were all detected in the non-amylolytic strain $L$. plantarum WCFS1 together with the gene $\alpha$-amy coding for an intracellular alpha-amylase, whereas the gene amyE coding for an extracellular alpha-amylase was detected only in the amylolytic strain L. plantarum A6 (Humblot et al., 2014). In the present study, the gene amyE was not detected in any of the metagenomes. Taken together, these results suggest poor amylolytic potential of the LAB in the porridge.

The genetic potential for the synthesis of carotenoids also appears to be low, since the operon crtNM was not detected in our study, whereas it was detected in $37 \%$ of LAB wild strains isolated from ben-saalga (Turpin et al., 2016). However, this previous work showed that the potential for carotenoid synthesis by these LAB is low, since only $36 \mathrm{LAB}$ strains among the 58 with positive PCR detection were able to produce carotenoids in MRS culture broth. In addition, even the highest carotenoid producing strain produced low amounts of carotenoids in a food matrix made from pearl-millet (less than $77 \mu \mathrm{g} \beta$-carotene equivalent per $100 \mathrm{~g}$ of dry cell weight).

As for microbial diversity, our results are in good agreement with previous studies that showed that $L$. fermentum was the dominant species found in different pearl-millet based fermented foods, including ben-saalga, (Lei and Jakobsen, 2004; Owusu-Kwarteng et al., 2012; Turpin et al., 2011). Indeed, in this study, L. fermentum was the most frequent species out of the four main species analyzed. Variability in the species investigated was observed among samples produced by different TPUs, which is in good agreement with the literature, but also among samples from the same TPU (Humblot and Guyot, 2009; Owusu-Kwarteng et al., 2012). Different factors could explain this microbial variability, for example the variability of the raw materials used. Vogelmann et al. (2009) demonstrated on sourdoughs 
prepared from cereals, pseudocereals and cassava that the raw materials have an impact on the composition of the microbiota. According to Tou et al. (2006), porridge producers in Burkina Faso use different aromatic ingredients, such as ginger and pepper, in addition to pearl-millet grains, which could also modify the microbial composition. As reviewed by Minervini et al. (2014), other parameters, such as the duration and temperature of fermentation can also influence the composition of the microbiota. The fermentation of ben-saalga is performed at ambient temperature and has a mean duration of 11 hours (overnight fermentation) with extreme values ( 2 to 20 hours) only in very few TPU (Tou et al., 2006). In our study, the different samplings in each TPU were carried out on five different days, on the final product ('ready to use' porridge, after cooking at the end of the fermentation). Therefore, the observed variability in the analyzed parameters (microbial variability, folate content, etc.) reflects that of the food as eaten by the consumer.

The variability of the concentrations of the main $\mathrm{LAB}$ responsible for the fermentation of bensaalga could have an influence on the variability of the genetic potential of the microbiota. However, the statistical analyses did not allow us to establish clear correlations between the concentration of each individual $\mathrm{LAB}$, and the detection of each gene.

In the present study, the genes folP and folK (coding for folate synthesis) were detected in $80 \%$ of the samples, suggesting that the LAB responsible for the ben-saalga fermentation have a high genetic potential to synthesize folate. A complementary mRNA based analysis on the dough before cooking would have indicated if those genes were expressed or not. But to determine if this genetic potential is consistent with the presence of the corresponding micronutrient, we measured total folate content in all 50 samples. However, the folate content of the pearl-millet based porridges was very low (median: $0.5 \mu \mathrm{g} / 100 \mathrm{~g} F \mathrm{~F}$ ) in comparison to other fermented foods (Souci et al., 2000). This porridge thus cannot be considered as a good source of folate, since 1- to 3-year-old children would have to eat about 3,000 g of porridge per day to reach only $10 \%$ of their recommended folate intakes, which is $150 \mu \mathrm{g} /$ day for 1 - to 3-year-old children (FAO/WHO, 2005). Considering that the process requires the addition of a large quantity of water to the dough, leading to a dry matter content of less than $10 \%$, the folate originally present in the food matrix was diluted. Nevertheless, from the folate content of the raw pearl-millet ( $29 \mu \mathrm{g} / 100 \mathrm{~g} \mathrm{FW}$; Stadlmayr et al. 2012), we calculated that the final folate content should be higher than $2.5 \mu \mathrm{g} / 100 \mathrm{~g} \mathrm{FW}$, if there was no loss of folate and only a dilution. This means that folate was probably degraded during the processing of pearl-millet 
into ben-saalga, due to the high sensitivity of this vitamin to oxidation, light, and variations in pH (Strandler et al., 2015). It may also be possible that folate was produced during fermentation, but in small quantities (not sufficient to compensate for the losses), or that it was consumed by the LAB during fermentation. Indeed, folate is involved in essential functions such as metabolism of amino acids, nucleotides synthesis and DNA replication, and therefore each microorganism needs to consume folate to grow (Ball, 2005). Numerous LAB strains belonging to different species such as L. fermentum and L. plantarum, as well as yeasts, are considered as folate-producing microorganisms since they are able to synthesize higher amount of folate than they consume (Hjortmo et al., 2005; Hugenschmidt et al., 2010; Masuda et al., 2012). But other LAB are considered to be folate-consuming microorganisms, since some of the genes coding for enzymes involved in the synthesis of folate are lacking in these LAB (Rossi et al., 2011). Therefore, the in situ content of folate might have been the result of a balance between auxotrophy and prototrophy.

To conclude, this study highlighted not only the variability of the composition of the microbiota among samples of fermented porridges produced by different TPUs, but also the variability of the composition of the microbiota among the samples produced by the same TPU. This work also shows that it is difficult to draw conclusions concerning the genetic potential of the microbiota of a naturally fermented food only by analyzing genes in metagenomes. The high frequency of the presence of genes does not necessarily correlate with in situ measurements of the expected product, e.g. relation between detection of genes coding for enzymes involved in folate synthesis and the low in situ folate content, observed here. In the case of folate, this could be due to the presence of folate-consuming LAB strains. The choice of another compound, whose consumption by microorganisms is not possible may be more appropriate when using genetic screening. Further studies could aim at optimizing the fermentation step in order to increase the folate content of pearl-millet based porridges. On the contrary, the absence of detection of some genes such as amyE appears to be linked with the absence of the corresponding function in the microbiota responsible for the fermentation. Such lack of detection would help, in further studies, to decide whether isolation of LAB with specific nutritional properties from fermented food should be considered or not.

\section{Acknowledgements}


The authors thank Christian Picq for collecting the samples in Ouagadougou, and for his help with the DNA extraction.

This work was carried out in the framework of the FolEA project (www.folea.eu), which is part of the ERA-Net «Developing African-European joint collaboration for Science and Technology » (ERAfrica), financially supported by the European Commission under the $7^{\text {th }}$ Framework Programme (ERAfrica ERAFRICA_IC-027, FP-226154).

Fabien Saubade acknowledges a $\mathrm{PhD}$ grant from the French Ministry of Education and Research.

\section{References}

Arsenault, J.E., Nikiema, L., Allemand, P., Ayassou, K.A., Lanou, H., Moursi, M., De Moura, F.F., and Martin-Prevel, Y. (2014). Seasonal differences in food and nutrient intakes among young children and their mothers in rural Burkina Faso. J. Nutr. Sci. 3, (e55): 1-9.

Ball, G.F.M. (2005). Vitamins In Foods: Analysis, Bioavailability, and Stability. Chapter 13. Folate. p. 231-274 (CRC Press).

Becquey, E., and Martin-Prevel, Y. (2010). Micronutrient Adequacy of Women's Diet in Urban Burkina Faso Is Low. J. Nutr. 140, 2079S-2085S.

Blount, B.C., Mack, M.M., Wehr, C.M., MacGregor, J.T., Hiatt, R.A., Wang, G., Wickramasinghe, S.N., Everson, R.B., and Ames, B.N. (1997). Folate deficiency causes uracil misincorporation into human DNA and chromosome breakage: Implications for cancer and neuronal damage. Proc. Natl. Acad. Sci. 94, 3290-3295.

Burgess, C.M., Smid, E.J., and van Sinderen, D. (2009). Bacterial vitamin B2, B11 and B12 overproduction: An overview. Int. J. Food Microbiol. 133, 1-7.

Capozzi, V., Russo, P., Teresa Duenas, M., Lopez, P., and Spano, G. (2012). Lactic acid bacteria producing B-group vitamins: a great potential for functional cereals products. Appl. Microbiol. Biotechnol. 96, 1383-1394.

Chagnaud, P., Machinis, K., Coutte, L.A., Marecat, A., and Mercenier, A. (2001). Rapid PCR-based procedure to identify lactic acid bacteria: application to six common Lactobacillus species. J. Microbiol. Methods 44, 139-148.

FAO/WHO (2005). Vitamin and mineral requirements in human nutrition, Second edition. http://www.who.int/nutrition/publications/micronutrients/9241546123/en/.

Garrido-Fernández, J., Maldonado-Barragán, A., Caballero-Guerrero, B., Hornero-Méndez, D., and Ruiz-Barba, J.L. (2010). Carotenoid production in Lactobacillus plantarum. Int. J. Food Microbiol. 140, 34-39.

Guyot, J.-P. (2012). Cereal-based fermented foods in developing countries: ancient foods for modern research. Int. J. Food Sci. Technol. 47, 1109-1114. 
Heilig, H.G.H.J., Zoetendal, E.G., Vaughan, E.E., Marteau, P., Akkermans, A.D.L., and Vos, W.M. de (2002). Molecular Diversity of Lactobacillus spp. and Other Lactic Acid Bacteria in the Human Intestine as Determined by Specific Amplification of 165 Ribosomal DNA. Appl. Environ. Microbiol. $68,114-123$.

Hjortmo, S., Patring, J., Jastrebova, J., and Andlid, T. (2005). Inherent biodiversity of folate content and composition in yeasts. Trends Food Sci. Technol. 16, 311-316.

Hugenschmidt, S., Schwenninger, S.M., Gnehm, N., and Lacroix, C. (2010). Screening of a natural biodiversity of lactic and propionic acid bacteria for folate and vitamin B12 production in supplemented whey permeate. Int. Dairy J. 20, 852-857.

Humblot, C., and Guyot, J.-P. (2009). Pyrosequencing of Tagged 16S rRNA Gene Amplicons for Rapid Deciphering of the Microbiomes of Fermented Foods Such as Pearl Millet Slurries. Appl. Environ. Microbiol. 75, 4354-4361.

Humblot, C., Turpin, W., Chevalier, F., Picq, C., Rochette, I., and Guyot, J.-P. (2014). Determination of expression and activity of genes involved in starch metabolism in Lactobacillus plantarum A6 during fermentation of a cereal-based gruel. Int. J. Food Microbiol. 185, 103-111.

Iwamoto, K., Tsuruta, H., Nishitaini, Y., and Osawa, R. (2008). Identification and cloning of a gene encoding tannase (tannin acylhydrolase) from Lactobacillus plantarum ATCC 14917T. Syst. Appl. Microbiol. 31, 269-277.

Jang, J., Kim, B., Lee, J., Kim, J., Jeong, G., and Han, H. (2002). Identification of Weissella species by the genus-specific amplified ribosomal DNA restriction analysis. FEMS Microbiol. Lett. 212, 29-34.

Kariluoto, S., and Piironen, V. (2009). Total folate. In: HEALTHGRAIN Methods: Analysis of Bioactive Components in Small Grain Cereals. Ed.: P. Shewry and J. Ward. St Paul, Minnesota, USA : AACC International, p 59-68.

Lei, V., and Jakobsen, M. (2004). Microbiological characterization and probiotic potential of koko and koko sour water, African spontaneously fermented millet porridge and drink. J. Appl. Microbiol. 96, 384-397.

Masuda, M., Ide, M., Utsumi, H., Niiro, T., Shimamura, Y., and Murata, M. (2012). Production Potency of Folate, Vitamin B-12, and Thiamine by Lactic Acid Bacteria Isolated from Japanese Pickles. Biosci. Biotechnol. Biochem. 76, 2061-2067.

Minervini, F., De Angelis, M., Di Cagno, R., and Gobbetti, M. (2014). Ecological parameters influencing microbial diversity and stability of traditional sourdough. Int. J. Food Microbiol. 171, 136-146.

Minervini, F., Lattanzi, A., De Angelis, M., Celano, G., and Gobbetti, M. (2015). House microbiotas as sources of lactic acid bacteria and yeasts in traditional Italian sourdoughs. Food Microbiol. 52, 66-76.

Mouquet-Rivier, C., Icard-Vernière, C., Guyot, J.-P., Hassane Tou, E., Rochette, I., and Trèche, S. (2008). Consumption pattern, biochemical composition and nutritional value of fermented pearl millet gruels in Burkina Faso. Int. J. Food Sci. Nutr. 59, 716-729.

Muyzer, G., Dewaal, E., and Uitterlinden, A. (1993). Profiling of Complex Microbial-Populations by Denaturing Gradient Gel-Electrophoresis Analysis of Polymerase Chain Reaction-Amplified GenesCoding for 16s Ribosomal-Rna. Appl. Environ. Microbiol. 59, 695-700. 
Omar, N. ben, and Ampe, F. (2000). Microbial Community Dynamics during Production of the Mexican Fermented Maize Dough Pozol. Appl. Environ. Microbiol. 66, 3664-3673.

Owusu-Kwarteng, J., Akabanda, F., Nielsen, D.S., Tano-Debrah, K., Glover, R.L.K., and Jespersen, L. (2012). Identification of lactic acid bacteria isolated during traditional fura processing in Ghana. Food Microbiol. 32, 72-78.

Rossi, M., Amaretti, A., and Raimondi, S. (2011). Folate Production by Probiotic Bacteria. Nutrients 3, 118-134.

Rouget, F., Monfort, C., Bahuau, M., Nelva, A., Herman, C., Francannet, C., Robert-Gnansia, E., and Cordier, S. (2005). Periconceptional folates and the prevention of orofacial clefts: role of dietary intakes in France. Rev. Epidemiol. Sante Publique 53, 351-360.

Singh, A. k, Rehal, J., Kaur, A., and Jyot, G. (2015). Enhancement of Attributes of Cereals by Germination and Fermentation: A Review. Crit. Rev. Food Sci. Nutr. 55, 1575-1589.

Souci, S., Fachmann, W., and Kraut, H. (2000). Food composition and nutrition tables, 6th revised and completed edition. CRC Press, p. 1182.

Stadlmayr, B., Charrondiere, U.R., Enujiugha, V.N., Bayili, R.G., Fagbohoun, E.G., Samb, B., Addy, P., Barikmo, I., Ouattara, F., Oshaug, A., et al. (2012). West African Food Composition Table - Table de composition des aliments d'Afrique de l'Ouest. FAO, Rome, Italy. Available from $<$ http://www.fao.org/infoods/tables_africa_en.stm> Accessed July 2016.

Strandler, H.S., Patring, J., Jägerstad, M., and Jastrebova, J. (2015). Challenges in the Determination of Unsubstituted Food Folates: Impact of Stabilities and Conversions on Analytical Results. J. Agric. Food Chem. 63, 2367-2377.

Svanberg, U. (1995). Lactic acid fermented foods for feeding infants. In: Steinkraus K.H. (Ed), Handbook of Indigenous Fermented Foods, Second Edition, Revised and Expanded. CRC Press, pp. 310-321. p.

Tou, E.H., Guyot, J.P., Mouquet-Rivier, C., Rochette, I., Counil, E., Traoré, A.S., and Trèche, S. (2006). Study through surveys and fermentation kinetics of the traditional processing of pearl millet (Pennisetum glaucum) into ben-saalga, a fermented gruel from Burkina Faso. Int. J. Food Microbiol. $106,52-60$.

Turpin, W., Humblot, C., and Guyot, J.-P. (2011). Genetic Screening of Functional Properties of Lactic Acid Bacteria in a Fermented Pearl Millet Slurry and in the Metagenome of Fermented Starchy Foods. Appl. Environ. Microbiol. 77, 8722-8734.

Turpin, W., Renaud, C., Avallone, S., Hammoumi, A., Guyot, J.-P., and Humblot, C. (2016). PCR of crtNM combined with analytical biochemistry: An efficient way to identify carotenoid producing lactic acid bacteria. Syst. Appl. Microbiol. 39, 115-121.

Viñas, B.R., Ribas Barba, L., Ngo, J., Gurinovic, M., Novakovic, R., Cavelaars, A., de Groot, L.C.P.G.M., van't Veer, P., Matthys, C., and Serra Majem, L. (2011). Projected Prevalence of Inadequate Nutrient Intakes in Europe. Ann. Nutr. Metab. 59, 84-95.

Vogelmann, S.A., Seitter, M., Singer, U., Brandt, M.J., and Hertel, C. (2009). Adaptability of lactic acid bacteria and yeasts to sourdoughs prepared from cereals, pseudocereals and cassava and use of competitive strains as starters. Int. J. Food Microbiol. 130, 205-212. 
Wickramasinghe, S.N. (2006). Diagnosis of megaloblastic anaemias. Blood Rev. 20, 299-318. 


\section{Figure captions}

Figure 1: Real-time PCR quantification of L. plantarum, L. fermentum, Leuconostoc and Weissella in fermented pearl-millet based porridges, sampled after the fermentation and the heating steps. Concentrations of microorganisms below the detection limit are not shown in the figure.

Figure 2: Folate content of the pearl-millet based porridge samples (FW: fresh weight basis) 
Table 1: List of primers used to screen the food metagenomes

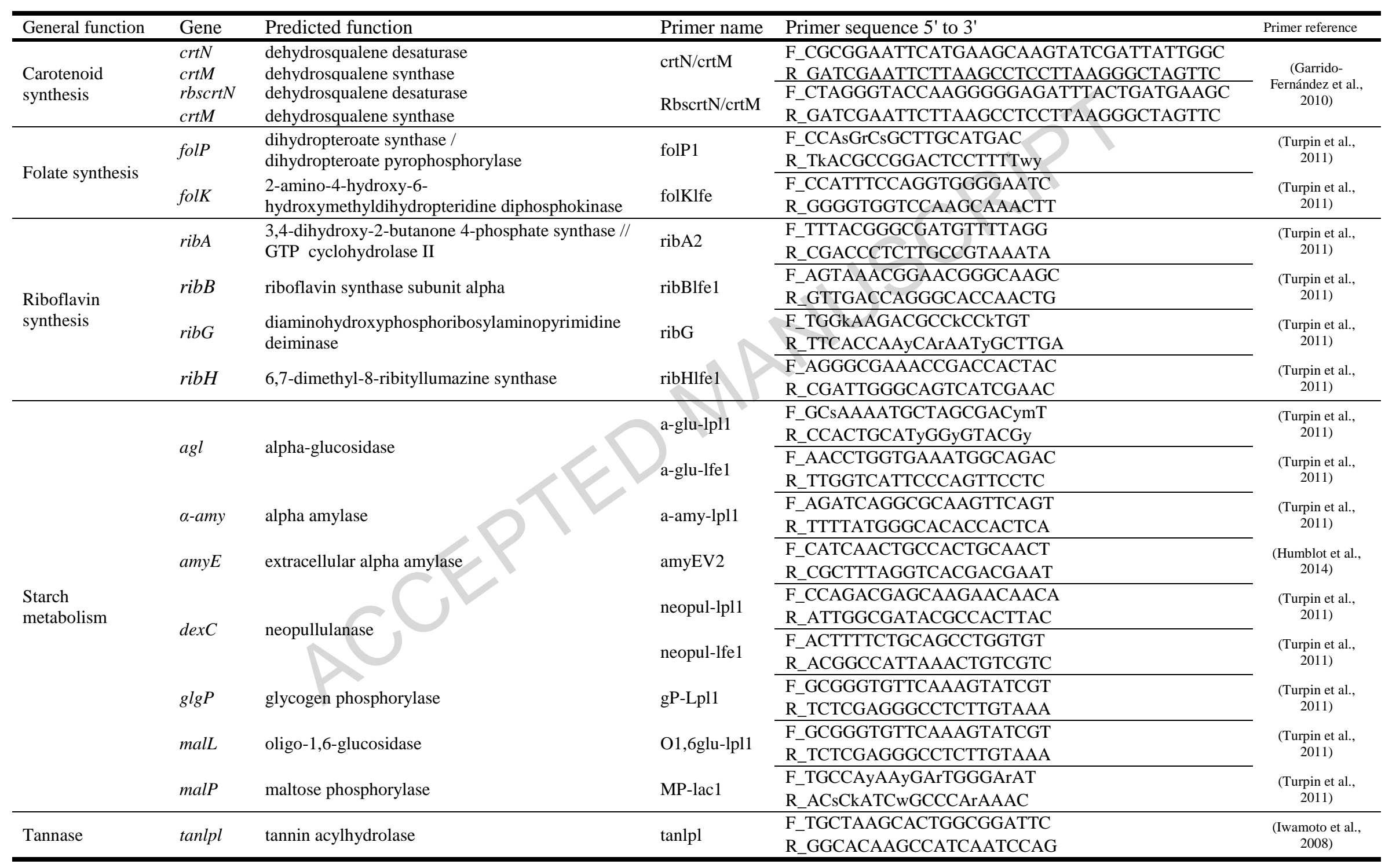


Table 2: Primers used to quantify the genus or species of bacteria from pearl-millet porridge samples using real-time PCR. The primers were designed to match the gene coding for 16S rRNA.

\begin{tabular}{llll}
\hline Name & Sequences 5'-3' & Targets & References \\
\hline $338 f$ & ACTCCTACGGGAGGCAGCAG & Bacteria & Muyzer et al. (1993) \\
$338 r^{*}$ & CTGCTGCCTCCCGTAGGAGT & Bacteria & Muyzer et al. (1993) \\
$518 r$ & ATTACCGCGGCTGCTGG & Universal & Muyzer et al. (1993) \\
Lab677r & CACCGCTACACATGGAG & Lactobacillus & Heilig et al. (2002) \\
Lab772r & YCACCGCTACACATGRAGTTCCACT & Lactobacillus & Omar and Ampe (2000) \\
Lab158f & TGGAAACAGRTGCTAATACC & LAB & Omar and Ampe (2000) \\
Lferm72f* & CCTGATTGATTTTGGTCGC & L. fermentum & Omar and Ampe (2000) \\
Lpla72f & ATCATGATTTACATTTGAGTG & L. plantarum & Chagnaud et al. (2001) \\
leu200f* & CGGCGTCACCTAGAGATGGATC & Leuconostoc & Omar and Ampe (2000) \\
S-G-Wei-0121-a-S-2 & CGTGGGAAACCTACCTCTTA & Weissella & \\
& & & Jang et al. (2002) \\
S-G-Wei-0823-a-A-18 & CCCTCAAACATCTAGCAC & Weissella & Jang et al. (2002) \\
\hline
\end{tabular}

* Primers from the literature were converted into their reverse complement 
Table 3: Distribution of genes involved in carotenoid, folate and riboflavin synthesis, starch metabolism and tannase synthesis in metagenomes extracted from pearl-millet porridges. Red boxes: the gene was not detected; Green boxes: the gene was detected; Grey boxes: the gene was detected, but more than one band was observed on the electrophoresis gel (non-specific detection).

\begin{tabular}{|c|c|c|c|c|c|c|c|c|c|c|c|c|c|c|c|}
\hline \multirow{2}{*}{\begin{tabular}{c}
$\begin{array}{r}\text { General } \\
\text { function }\end{array}$ \\
\multirow{\Xi}{\Delta}{}
\end{tabular}} & \multirow{2}{*}{ Carotenoids } & \multicolumn{2}{|c|}{ Folate } & \multicolumn{4}{|c|}{ Riboflavin } & \multicolumn{7}{|c|}{ Starch metabolism } & \multirow{2}{*}{$\frac{\text { Tannases }}{\text { 蔦 }}$} \\
\hline & & $\stackrel{\square}{\infty}$ & $\frac{\Xi}{5}$ & $\underset{Z}{\mathbb{Z}}$ & 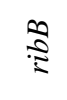 & : & $\underset{\mathbb{Z}}{\mathbb{2}}$ & $\overline{80}$ & $\begin{array}{l}\text { ऐે } \\
\text { ذे } \\
\text { ปे }\end{array}$ & $\begin{array}{l}\text { ग) } \\
\text { है }\end{array}$ & \begin{tabular}{l} 
U̦ \\
\multirow{J}{*}{}
\end{tabular} & $\frac{0}{00}$ & $\stackrel{\Xi}{\Xi}$ & $\stackrel{\Xi}{\Xi}$ & \\
\hline \multicolumn{16}{|l|}{$\mathrm{A} 1$} \\
\hline \multicolumn{16}{|l|}{$\mathrm{A} 2$} \\
\hline \multicolumn{16}{|l|}{ A3 } \\
\hline \multicolumn{16}{|l|}{ A4 } \\
\hline \multicolumn{16}{|l|}{ A5 } \\
\hline \multicolumn{16}{|l|}{ B1 } \\
\hline \multicolumn{16}{|l|}{ B2 } \\
\hline \multicolumn{16}{|l|}{ B3 } \\
\hline \multicolumn{16}{|l|}{ B4 } \\
\hline B5 & & & & & & & & & & & & & & . & \\
\hline $\mathrm{C} 1$ & & & & & & & & & & & & & & & \\
\hline $\mathrm{C} 2$ & & & & & & & & & & & & & & & \\
\hline C3 & & & & & & & & & & & & & & & \\
\hline $\mathrm{C} 4$ & & & & & & & & & & & & & & & \\
\hline C5 & & & & & & & & & & & & & & & \\
\hline D1 & & & & & & & & & & & & & & & \\
\hline D2 & & & & & & & & & & & & & & & \\
\hline D3 & & & & & & & & & & & & & & & \\
\hline $\mathrm{D} 4$ & & & & & & & & & & & & & & & \\
\hline D5 & & & & & & & & & & & & & & & \\
\hline E1 & & & & & & & & & & & & & & & \\
\hline E2 & & & & & & & & & & & & & & & \\
\hline E3 & & & & & & & & & & & & & & & \\
\hline E4 & & & & & & & & & & & & & & & \\
\hline E5 & & & & & & & & & & & & & & & \\
\hline F1 & & & & & & & & & & & & & & & \\
\hline F2 & & & & & & & & & & & & & & & \\
\hline F3 & & & & & & & & & & & & & & & \\
\hline F4 & & & & & & & & & & & & & & & \\
\hline F5 & & & & & & & & & & & & & & & \\
\hline G1 & & & & & & & & & & & & & & & \\
\hline G2 & & & & & & & & & & & & & & & \\
\hline G3 & & & & & & & & & & & & & & & \\
\hline G4 & & & & & & & & & & & & & & & \\
\hline G5 & & & & & & & & & & & & & & & \\
\hline $\mathrm{H} 1$ & & & & & & & & & & & & & & & \\
\hline $\mathrm{H} 2$ & & & & & & & & & & & & & & & \\
\hline $\mathrm{H} 3$ & & & & & & & & & & & & & & & \\
\hline $\mathrm{H} 4$ & & & & & & & & & & & & & & & \\
\hline H5 & & & & & & & & & & & & & & & \\
\hline I1 & & & & & & & & & & & & & & & \\
\hline I2 & & & & & & & & & & & & & & & \\
\hline $\mathrm{I} 3$ & & & & & & & & & & & & & & & \\
\hline I4 & & & & & & & & & & & & & & & \\
\hline I5 & & & & & & & & & & & & & & & \\
\hline $\mathrm{J} 1$ & & & & & & & & & & & & & & & \\
\hline $\mathrm{J} 2$ & & & & & & & & & & & & & & & \\
\hline J3 & & & & & & & & & & & & & & & \\
\hline $\mathrm{J} 4$ & & & & & & & & & & & & & & & \\
\hline J5 & & & & & & & & & & & & & & & \\
\hline
\end{tabular}




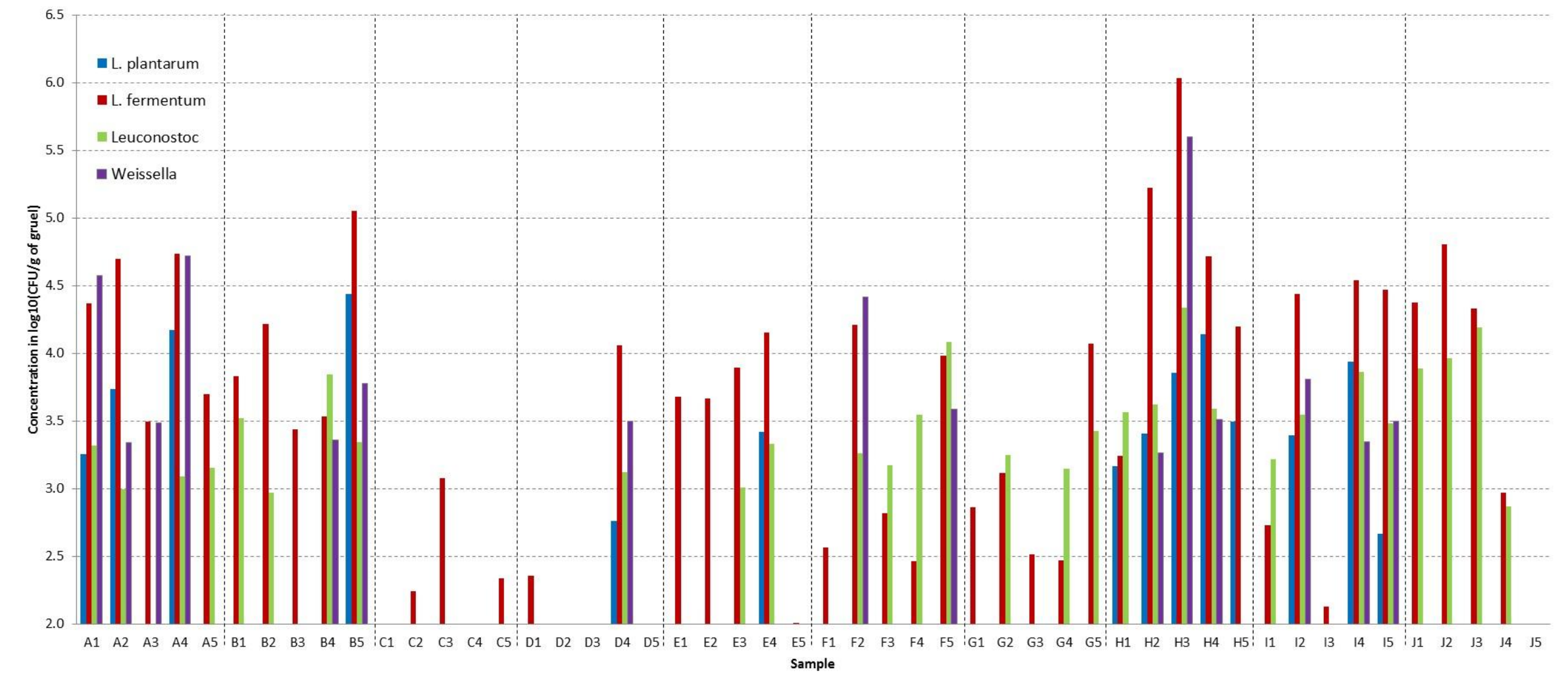

Figure 1 


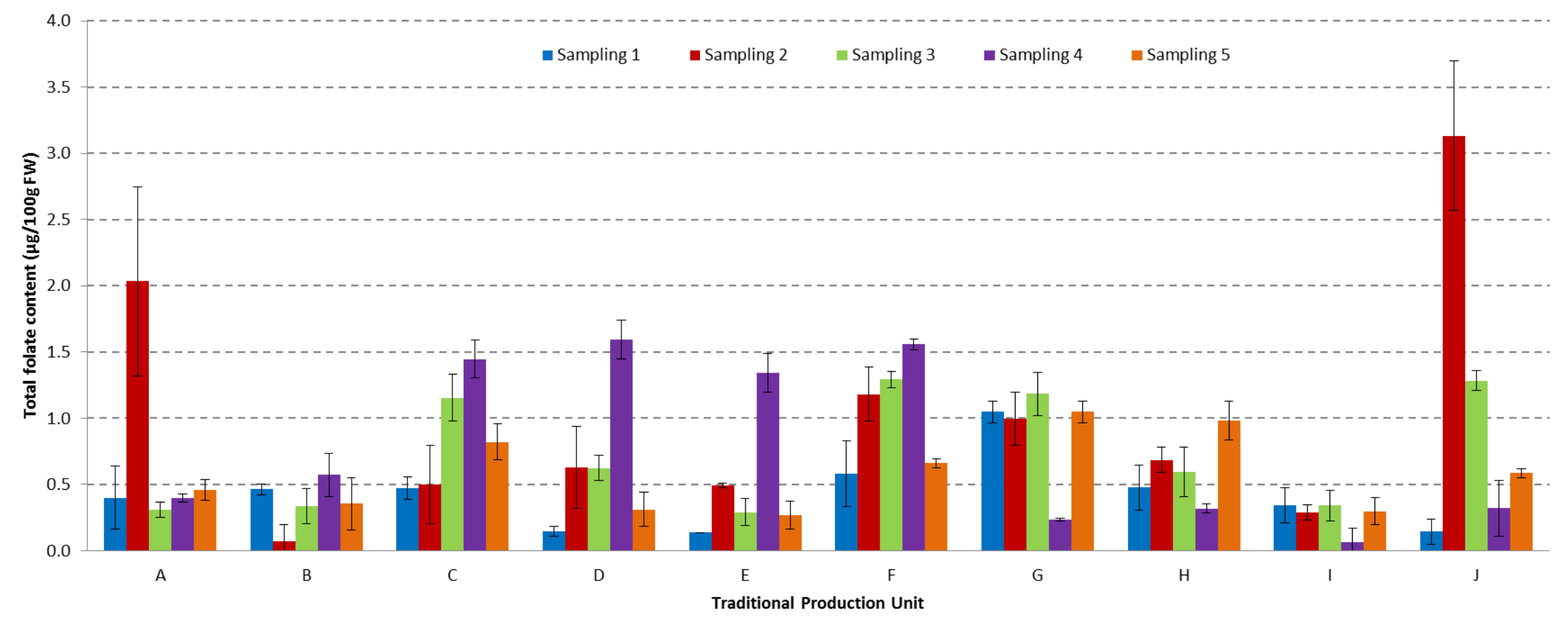

Figure 2 
Highlights ( 3 to 5 bullet points; maximum 85 characters, including spaces, per bullet point)

- Genes encoding enzymes involved in various functions were sought in metagenomes

- The genetic potential for different nutritional functions varied among food samples

- Microbial composition varied among samples from the same production unit

- The genetic potential for folate synthesis was high in metagenomes

- Yet, the folate content of the pearl-millet based porridges was very low 